\title{
Tell-tale signs: Reflection towards the acquisition of academic discourses as second languages
}

\author{
Louise Olivier \\ Africa \\ Email: louise.olivier@nwu.ac.za \\ Jako Olivier \\ School of Languages, Potchefstroom Campus, North-West University, South Africa \\ Email: jako.olivier@nwu.ac.za
}

Centre for Academic and Professional Language Practice, Potchefstroom Campus, North-West University, South

\begin{abstract}
Parallels can be drawn between the acquisition of academic discourses and second languages. After enrolling in a sign language course, we - lecturers teaching academic discourses decided to explore this phenomenon and determine the implications for pedagogical practice. Themes and codes were identified through qualitative analysis of reflection journals compiled during the course. It is suggested that pedagogical practice could be improved by adapting pace and lesson structure to students' needs. It is clear that motivation is important for skills acquisition and can be facilitated by the creation of learning communities and accommodating different learning styles through differentiation. A safe learning environment is essential where a learning community is supported by effective use of technology. Additionally, an adequate balance of suitable content, opportunities for learning by example, having sufficient tools to reach measureable outcomes as well as creating opportunities for reinforcement of skills could all benefit the teaching of academic discourses.
\end{abstract}

Keywords: academic discourses, second language acquisition, reflection, tertiary pedagogical practice

\section{Introduction}

The acquisition of academic discourses can be considered to be similar to the acquisition of a second or additional language. Gee (1989:7) claims that much that is considered "true of second language acquisition or socially situated cognition [is also] true of the acquisition of Discourses". In this regard, we - as lecturers facilitating the acquisition of academic discourses in generic and subject-specific contexts - decided to explore the aforementioned notion by becoming students again. In this qualitative study, we reflected on our experiences 
while doing a South African Sign Language (SASL) course in order to determine whether these could benefit our teaching practice in terms of the acquisition of academic discourses.

This research is essential as it not only strongly supports the importance of reflection while learning as well as being immersed in situations similar to those experienced by students, but it is also a way in which to better pedagogical practice as part of the scholarship of teaching and learning (Kreber 2002:6, Trigwell and Shale 2004:524). We have experienced that students not only react negatively to certain aspects of the teaching and learning of academic discourses, but that they also do not transfer all aspects of the set of academic skills (cf. Henderson and Hirst 2006:2) to modules done later in their academic careers. This lack of transfer is but one aspect of lecturers' concerns regarding academic literacy and perceived substandard undergraduate student writing (Boughey 2000:282, Lillis and Turner 2001:57, Jackson, Meyer and Parkinson 2006:266).

The aim of this article is to explore whether parallels exist between the acquisition of academic discourses and the acquisition of an additional language as well as the implications this has for the teaching of academic discourses. To this end, a theoretical contextualisation is provided in order to explain the context in which academic discourses take place, what is meant by academic discourses and how the literature views second language acquisition. Furthermore, the empirical research, which takes the form of a qualitative analysis of reflective journals, is discussed in terms of the background, procedure, analysis as well as relevant findings and recommendations.

\section{Contextualisation}

Massification and diversification of higher education is evident from the literature (Fraser and Killen 2003:254, Street 2004:9, Larrivee and Cooper 2006:1). Furthermore, due to the poor literacy levels of many students, universities realise that they need to support their students and this support realises in literacy support courses of a generic and/or a subject-specific nature. Universally, tertiary institution lecturers complain about substandard undergraduate student writing (Boughey 2000:282, Lillis and Turner 2001:57, Jackson, Meyer and Parkinson 2006:266) hence courses with modules focusing on academic discourses or specialised academic literacy courses are made compulsory at universities.

As background to the reflection of two lecturers of academic discourses who attended a SASL second language course, it is firstly important to give an overview of SASL and then explain what the concept of 'academic discourses' entails. In addition, some background is given on second language acquisition in order to determine, by means of reflection, what similarity exists between the acquisition of a second language and academic discourses as well as the implications it holds for pedagogical practice.

\subsection{South African Sign Language}

SASL, like other sign languages, is a visual language through which speakers use their hands, facial expressions and upper body to communicate (Akach and Naudé 2008:4, Druchen 2007). It is important to mention here that sign language is not universal and varies according to geographic region (Druchen 2007). SASL is not an official language, but according to the 
South African Constitution (1996), this language should be promoted and developed (Aarons and Akach 2002:129).

SASL could be considered as being semiotically different from non-visual languages. In this regard, the acquisition of such a language poses specific challenges to users of non-visual languages when learning a visual language such as SASL. This article specifically explores the context of learning a language such as SASL as being similar to students' experiences when encountering academic discourses in higher education.

\subsection{Academic discourses}

In order to consider the acquisition of academic discourses, it is important to define what is understood by this concept. Hyland (2009:1) defines academic discourse as "the ways of thinking and using language which exist in the academy". He highlights the importance of academic discourse by stating that "[d]iscourse, and particularly student writing, is at the centre of teaching and learning in Higher Education" (Hyland 2009:5). However, in this article, the term "discourses" is used to emphasise the fact that individuals maintain different discourses such as the primary and secondary discourses (Gee 1989:8-10), and that different discourses are required between academic disciplines or even subdisciplines (Elbow 1991:138-140).

The concept of 'discourses' is also described by Gee (1989:6) as follows:

At any moment we are using language we must say or write the right thing in the right way while playing the right social role and to hold right values, beliefs, and attitudes. Thus, what is important is not language, and surely not grammar, but saying (writing)-doing-being-valuing-believing combinations.

Gee (1989:6) actually distinguishes between "discourse" as "connected stretches of language" and "Discourse" (with capitalisation) as the wider combination of aspects mentioned before. Similarly, with second language acquisition, focus cannot only be on language-in-use (discourse); it also involves the greater context and community of a language (Discourse) such as sociolinguistic and sociocultural competence (Littlewood 2004:503). However, for the sake of this article, the term "discourse" is used to mean what Gee (1989) considers as "Discourse". It is also assumed in this article that academic discourses are dynamic, not governed by arbitrary prescriptions and specific to various disciplines (Kutz 1986:385).

As stated in the introduction, the impetus for this study is the fact that Gee (1989:7), also supported by Kutz (1986:387, 392), regards the acquisition of discourses as being similar to second language acquisition.

\subsection{Second language acquisition}

The concept of 'second language acquisition' refers to the learning of an additional language or the creation of new language systems (Gass and Selinker 2008:1). For the purposes of this article, and as is generally accepted in the literature (Littlewood 2004:502), the scope does not refer only to a learnt second language, but to any additional language. 
Theories of second language acquisition are either based on cognitive processes or the context of learning (Littlewood 2004:514, Van Patten and Benati 2010:71). A brief overview of second language acquisition theories is presented below. Note, however, that we are in no way presenting this as an exhaustive and complete overview of this dynamic field of study.

Cognition-oriented theories involve language learning taking place by means of innate mechanisms. Hence, the Creative Construction hypothesis implies that language learners have innate mechanisms with which to process language. In terms of the Input hypothesis, a distinction exists between the subconscious process of acquisition and conscious learning. Here, acquired language is regarded as important since it relates to spontaneous communication, while the language that was learnt only acts as a monitor. The Universal Grammar hypothesis relates to individuals having universal principles governing all languages being set in the brain. According to the Cognitive Skill-Learning model, language skill is determined by a hierarchy of cognitive plans (Ellis 1985:261, Gass and Selinker 2008:129-133, Krashen 1981:2, 100-136; Kutz 1986:388, Littlewood 2004:515-517, Van Patten and Benati 2010:2-4, 47, 60-61, 96, 162-163).

Context-oriented theories involve the learning context and how it contributes to the learning process. The Interaction hypothesis requires comprehensible input through social interaction. In contrast, the Output hypothesis states that input is not enough and that output or language production is also important for language acquisition. With the Scaffolding hypothesis, the emphasis is on support from others, relating also to Vygotsky's (1978:84-91) concept of the 'zone of proximal development', where a learner can achieve more by means of guidance or collaboration with others than when s/he works independently. The Acculturation model relates to language learning as part of acculturation where there might be social and psychological distance between a learner and speakers of a target language. Similarly, the Social Identity model focuses on the link between language and identity, and the adaptation of this identity within a new community (Ellis 1985:251-253, Gass and Selinker 2008:293-295, Littlewood 2004:518-520, Van Patten and Benati 2010:5, 59, 144-145, 151-152).

When learning a second language, one draws on the language knowledge of one's mother tongue, what is known about the second language as well as how the second language can be used in different circumstances, i.e. transfer and generalisation take place (Littlewood 2004:504-508). Furthermore, simplification by means of omitting redundant elements and imitation of memorised language samples are also features of the language used by individuals when in the process of acquiring a new language (Littlewood 2004:508-509). Littlewood (2004:509) notes that, in terms of imitation, these language samples are processed internally by language learners "so that the underlying rules gradually become incorporated into their developing linguistic competence". The creation of interlanguages, which occurs during second language acquisition, can also be relevant for second language acquisition (Kutz 1986:392).

Littlewood (2004:512) states that "[i]n studies which have compared learners who experience only natural exposure with learners who experience exposure and classroom instruction, the results (though less conclusive) also indicate that instruction improves learning". In this regard, clear instruction accelerates the rate of language learning, language form needs to be explicitly taught and language learners need to be actively involved (Littlewood 2004:512514). 
Research conducted on the influence of attitudinal or effective factors (Gass and Selinker 2008:452-464, Van Patten and Benati 2010:43, 62, 111) in second language acquisition is also important. Krashen (1981:21) states that if the affective filter is up, i.e. the language learners are not positive towards learning the language, learning does not take place, regardless of the nature of the teaching. The advantage of a positive motivation towards language learning amongst students as well as the use of motivational strategies is clear from the literature (Guilloteaux and Dörnyei 2008). Peirce (1995:17), however, argues that motivation cannot necessarily describe the complex relations between power, identity and language learning, and prefers to use the term "investment". Motivation, or investment, is just as important for the acquisition of academic discourses or academic literacy (Olivier and Olivier 2013:58, 68).

The aforementioned theoretical background provides a point of departure for the identification of parallels in terms of the acquisition of academic discourses and second languages. Prior to relating the analysis of the qualitative data, the research context and motivation is presented.

\section{Research context and motivation}

The teaching context within which we work involves a first-year Afrikaans and Dutch module and a compulsory academic literacy module at North-West University's Potchefstroom Campus. In both modules, students are exposed to the conventions of academic discourse and academic writing and teaching is conducted by means of various approaches to writing, including the product, process and genre approaches (Badger and White 2000:153, Jordan 1997:164, Swales 1990:58). The students in the Afrikaans and Dutch module (around 170 students for one semester) were mainly completing BA degrees in languages and communication studies, with some individuals from other fields such as theology, psychology and law. The students from the academic literacy module (around 500 students over two semesters) came from different faculties. All of these students had Afrikaans as a mother tongue and were studying mainly with Afrikaans as medium of instruction. As in the academic literacy module, some conventions of academic discourse are repeated in the Afrikaans and Dutch module, with the focus on how these conventions are used in a discipline-specific context. After informal discussions, we wondered why, after two modules, first-year students were still unable to produce even basic evidence of academic writing as is expected from them. Was it the students' past experiences with writing that were influencing them at tertiary level, or was it our own teaching abilities that were hindering their progress? Why were the students struggling so much?

We decided to put ourselves in the shoes of first-year students and enrol in a short course in SASL. This course was led by a Deaf colleague at the School of Languages. We quickly realised that learning SASL could be compared with learning a new discourse such as firstyear students who are expected to learn academic discourse. Initially, all we wanted to do was to learn a new language and invest in the target language (cf. Peirce 1995:17-18). However, after our first class, we realised that the tables had been turned - we were now on the other side; we were the students. This seemed like a good opportunity to reflect on our own teaching practices and how our students must feel when they sit behind the desks. 


\section{Reflection towards understanding learning experience}

In this study, we used journals to facilitate reflection on language learning and on our own pedagogical practices. In this way, we as lecturers become students; as O'Brien and Guiney (2001:1) put it, "[a]1l teachers are learners". According to Boud, Keogh and Walker (1985:17), reflection "in the context of learning is a generic term for those intellectual and affective activities in which individuals engage to explore their experiences in order to lead to new understandings and appreciations". According to Andrusyszyn and Davie (1997:105), journal writing as a "form of dialogical learning has been espoused as a means of facilitating reflection, promoting personal growth, and precipitating change".

Reflection is also not only a process of looking back, but entails some forward projection, as Jay (2003:6) states: "Procedurally, reflection entails looking forward to goals we might attain, as well as casting backward to see where we have been". She also notes that "we project and review, working dialectically as we seek to discover what we know and what we have learned" (Jay 2003:6). The method with which we compiled the journals, and ultimately analysed the data contained therein, is discussed in the subsequent section.

\section{Methodology}

\subsection{Data collection}

In this study, a qualitative method of data collection was used. We independently wrote journal entries, reflecting on our experience of learning SASL during an intensive short course offered to lecturers over a period of a month. The course involved a basic introduction to SASL focusing on finger spelling, basic phrases, basic grammar and a lot of terminology. Even though we attended the course together and "studied" together, the journals were written independently and the content was never discussed before the analysis of the data.

A journal was kept because "[t]he act of maintaining and reviewing a journal over time can serve as a useful tool for reflection" and "[h] aving a record of thoughts, feelings, issues, and concerns can provide both a window of the past and a gateway to the future" (Larrivee and Cooper 2006:21). Furthermore, Larrivee and Cooper (2006:21) point out that "journal writing as a systematic self-reflection process enables teachers to recognise their contribution to the experiences they encounter in the classroom. Making regular journal entries can help teachers become more aware of what is going on in both their inner and outer worlds". The journals in this study were kept electronically and could easily be imported into the Atlas.ti (2014) software for qualitative data analysis.

\subsection{Data analysis}

Inductive coding was done by means of Atlas.ti (2014) qualitative data analysis software (Saldaña 2009:111). The coding was done by both researchers for the sake of intercoder agreement (Saldaña 2009:27). A selection of quotations illustrating the identified codes is listed in the subsequent subsections with the author and quotation number at the start of each quotation. Figure 1 shows the summary of the codes and themes as a network. 


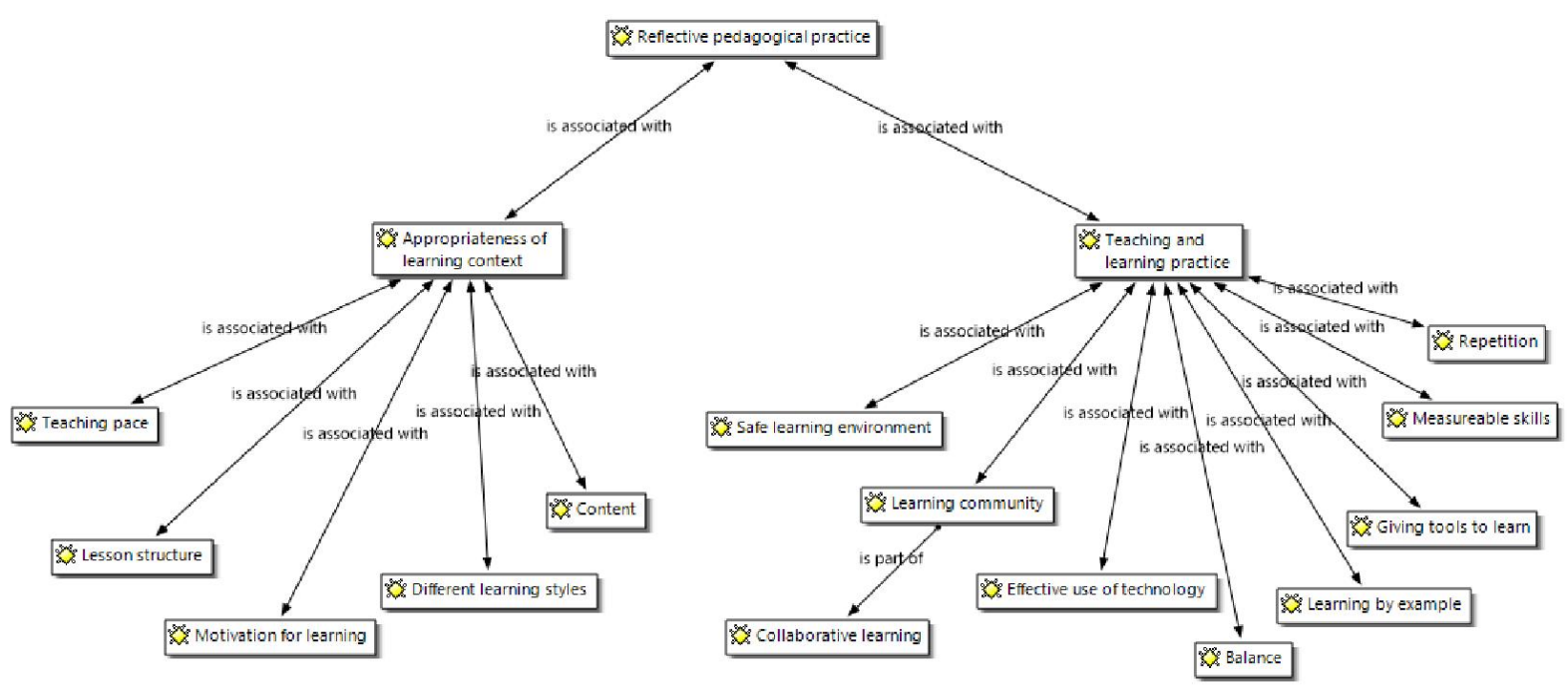

Figure 1. Themes and codes identified from the reflection journals

\subsubsection{Theme 1: Appropriateness of learning context}

The first theme identified relates to how appropriate the learning (and teaching) context is in order for language acquisition to take place. In this regard, the following codes were identified: teaching pace, lesson structure, motivation for learning, different learning styles and content.

\section{Code: Teaching pace}

Due to the nature of the SASL course, a large amount of content was included in the course. In addition, due to the nature of sign language, much time is spent on learning new terminology. SASL, like other sign languages, is a visual language through which speakers use their hands, facial expressions and upper body to communicate (Aarons and Akach 2002:137-138, Akach and Naudé 2008:4). The following comments were made with regard to teaching pace:

1.07: I immediately transposed it to my own classes and wondered whether I too was going too fast for some of the students dealing with new subject matter.

1.15: Unfortunately talking to $(\ldots)^{1}$ after class - she was negative and said that she would not attend again as the pace was too fast for her - she said it was a horrible feeling - hope the students don't feel like that after my classes.

1.62: [...] I felt too shy and embarrassed to ask (...) to teach the numbers again. Hope I don't make my students feel like that.

As with any language class, pace needs to be adapted to the needs of students. The key is student-centred differentiation. However, this might not always be possible in all lessons at university level as time is already limited and classes are sometimes quite large. In the same way, pace is also important in the teaching of academic discourses as students might also have different requirements and be at different levels in terms of the acquisition of these discourses. Similarly, the lesson's structure also requires careful planning.

\footnotetext{
${ }^{1}$ For sake of anonymity, (...) is used instead of the names recorded in the journal.
} 


\section{Code: Lesson structure}

Concerns regarding lesson structure do not imply customising lesson structures around the needs of students, but clear planning and organisation is essential.

1.12: I was frustrated that the first class was the alphabet and numbers - wanted to know how to say hello first - have to rethink my own classes what content to do what.

1.35: Unlike the previous class I do not know what to expect from the next lesson...

1.48: We did not have a lot of time to exercise the new concepts in the class and I am not clear what to expect of the next lesson.

The order of lessons and content should not only scaffold (Van Patten and Benati 2010:144-145) and build on existing knowledge, but should also prompt students to be interested in the content and outcomes. From the responses, the need for set outcomes and lesson content overviews is evident. Finally, the planning of lessons should also include ample time for repeating and practising skills (Van Patten and Benati 2010:141). The aforementioned issues also relate to the motivation of students.

\section{Code: Motivation for learning}

As stated before (cf. section 1.2), attitudinal or affective factors play a role in the acquisition of second languages. Some responses also related to these factors, especially in terms of motivation.

1.54: As I sit here practising the signs I wonder if my students are motivated to practise/incorporate what they have learnt that day in class (do I give them reason to practise/is the content so that they can/want to revise?).

1.73: Saw (...) on campus today. We greeted each other in sign. Was sooooooo awesome to be able to apply learnt knowledge in context.

1.87-88: Sitting here I am quite sad. Have not practised and when I try to recall I realise that I have even forgotten some of the alphabet :( Also, have moved to a new office and building and won't be seeing (...) that often - thus will probably not get to practise or use my new skills :( I must teach my students and equip them with skills that they will REALLY use!

2.94: [...] this course has opened up a new culture and even a better understanding for people without hearing. The motivation to learn this language has been driven by more than just an urge to know it, but also to be able to use it.

Teaching should not only focus on learning outcomes and content, but also on motivating students to practise their skills and creating suitable situations (Guilloteaux and Dörnyei 2008:55, 72-73). In this way, an investment can be made in terms of an additional discourse (Peirce 1995:16-18). As we recognised the use of SASL in communicating with Deaf people and peers in class, so must the use of academic discourses also be evident for our students. Academic discourses should not be confined to mere assessment opportunities, but should prepare students for real-life situations. In the same way that SASL introduced us to the world of Deaf people, so should academic discourses open students up to academia, academic 
"culture" and possibly even the world of work outside of university. In this process, however, students' different preferences with regard to learning should also be accommodated.

\section{Code: Different learning styles}

Students learn in different ways and may find themselves at different levels of acquisition; this was also observed in the SASL class.

1.24: [...] do I give enough space for differentiation and for students who want to do more than the basics?

1.44: I think I sometimes take knowledge for granted or expect students to know certain things. Students need rules and clear instruction.

Differentiation in learning (O'Brien and Guiney 2001) should extend to accommodating students who struggle with the basics and have to catch up as well as accomplished students who might require extension activities that challenge them. Differentiation is necessary at universities as "the learning process involves humans who are diverse in their needs, development, attitudes, values and beliefs" (O'Brien and Guiney 2001:1). Differentiation also relates to the content covered in courses. In this regard, when teaching academic discourses, it might be relevant to also teach non-academic discourses as part of university language or academic literacy courses (Elbow 1991:136-138). Furthermore, there needs to be a dialogue between lecturers and students in terms of instructional strategies. Brown (2009:56) states that there is a need for 'teachers to explore their students' perspectives on concrete pedagogical practices in the classroom and to share, selectively, their rationale and justifications for integrating certain activities, in order to inform and motivate their students". The same would apply in any course relating to academic discourses. As suggested by Kutz (1986:385, 392395), in order to accommodate students' needs, it might be necessary to start with the languages that students already use and work towards an "interlanguage as middle ground" rather than ideal academic discourses. The choice and handling of content also relates to the accommodation of students' needs as they are intertwined with the relevant instructional strategies.

\section{Code: Content}

The selection of content handled in class also prompted some responses in the journals.

1.26: When we started doing sentences, I realized that I had to relearn linguistic conventions.

2.33: I do realise that the couple of lessons will only provide me with very basic skills and as with any other skill this does require prolonged practice, a lot of commitment and a context in which the sign language skill will be used and practised often.

1.82: In the last class we did not learn any new words. (...) wanted us to "talk" to one another. In the beginning I felt like a fish out of water and was quite shy and embarrassed. However, everything I had learnt came back and it was quite fun to be able to communicate, even if just basically. 
The link with prior knowledge, in terms of content, is evident from the responses. However, quotation 1.26 also relates to certain skills that had to be relearnt. Furthermore, the number and duration of contact sessions influence how much content can be facilitated per contact session. A suitable balance should be maintained between the introduction of new content and practice or revision of already-taught content.

The next theme drawn from the remaining codes identified in the journals relates to the way in which teaching and learning practice can be adjusted for the acquisition of academic discourses based on experiences in a second language SASL class.

\subsubsection{Theme 2: Teaching and learning practice}

The reflection of the experiences of being students again prompted many issues regarding teaching and learning practice such as a safe learning environment, the learning community, the effective use of technology, balance, learning by example, giving tools to learn, measureable skills and repetition.

\section{Code: Safe learning environment}

It is important that a safe learning environment be created in which students can practise the skills acquired in class.

1.30: After class during a coffee break, some of us spontaneously practised some of the signs we had learnt in class - realized the importance of learning from others - as some explained how they remembered the words and with others - felt safer practising together and away from criticism...

Having the opportunity to practise skills with peers allows for safe learning environments to be created, even outside of the formal classroom situation. Yet, it is also important to extend the facilitation of safe environments to classroom situations. The creation of learning communities therefore also has an important role to play in this regard.

\section{Code: Learning community}

Two levels of community were evident from the journal entries for this study: the individuals that attended the SASL course comprised members of the Deaf community as well as the learning community.

1.34: By giving us all our own sign names and welcoming us all into the Deaf community, I realized that learning must include the individual in the group and a safe learning environment, where everyone feels included, is needed.

1.81: I realise that (...) seems to take over the class at times - I must take care that I don't allow students to do that in my own classes.

2.11: The deaf lecturer's enthusiasm and statement that he was looking forward to be able to communicate with more people at work served as encouragement for the whole class.

2.67: What a feeling to be able to actually speak to a Deaf person. 
As the SASL course introduced the course participants to Deaf culture and the Deaf world, so can courses relating to academic discourses introduce students to academia. The challenge with regard to the context of academic discourses is to find equivalents for, for example, the assignment and use of sign names. The desire to be part of or at least experience the Deaf community is a good motivation towards the acquisition of the language. In the same way, entrance to the academic community can also be facilitated. In the creation of the learning community in the SASL class, the same advantages can be experienced as were set out in terms of the zone of proximal development (Vygotsky 1978:84-91). In this community, technology was also employed by some of the students. For example, videos were shared between all members of the learning community by means of Dropbox.

\section{Code: Effective use of technology}

Some of the SASL course participants spontaneously started using iPads to record parts of the classes.

1.56: Am really excited! One of my classmates sent everyone in the group the video recordings that she made in class with her iPad via Dropbox. Wondering if I could do the same for my students.

2.86: Some of the students are making recordings, but I have but once looked at the recordings and as I found it difficult to find the individual words I have decided not to waste time on it at this stage.

The use of technology, especially technologies able to record videos in a SASL class, is clearly useful. From the quotations, it is evident that the use of recording technologies such as an iPad, shows opportunities regarding revision of signing done in class as well as being able to share recordings online between course participants. In this regard, the concept of 'lesson capturing' should also be considered for academic discourses classes. However, as shown in quotation 2.86, care should be taken that the technology is used and implemented effectively. In the case of acquiring terms, for example, it may be sensible to separate videos in order to have distinct files for each word or concept. A further concern is that using a recording device during class detracts from proper observation of the lecturer and fellow students, and even being able to practise all signs being learnt. Essentially, technology should support learning and teaching, and not be used for the sake of using technology. Technology can also be used to address problems regarding the balance of what is taught and what can be acquired in a contact session, as we shall see in the following subsection.

\section{Code: Balance}

The reflections on the SASL course's contact sessions show that we felt that too much content was taught in some sessions.

\subsection{2: $[\ldots]$ we did learn a lot or rather a lot was taught!}

This code also relates to the Content code, as not only should the nature of content be chosen carefully, but also the volume per lesson. In terms of balance, the quotation above relates to the large amount of information conveyed in a lesson as opposed to how much could actually be acquired within a lesson. This experience in the second language class prompted questions 
regarding whether enough (and even ongoing) time is spent on the teaching and learning of academic discourses. A semester or year-long course, as in the case of the first-year Afrikaans and Dutch module and compulsory academic literacy modules (cf. Olivier and Olivier 2013:57), might not be enough to facilitate the successful acquisition of academic discourses, and emphasis should be on continued support by all lecturers in this regard. In addition to the concerns regarding balance in the classroom, pedagogical issues such as the use of examples, learning tools, focus on measureable skills and repetition, were also evident from the data.

\section{Code: Learning by example}

One of the benefits of learning within a community (cf. Code: Learning community above) is the fact that students can learn from one another.

1.07: I realised that I was thankful for (...) and (...) sitting in front of me and when I forgot a sign I could copy them.

1.10: Learn by doing HELPS!

With regard to the SASL course, students could mimic each other if signs were repeated as a group. Confidence can be built by this cooperative learning strategy. In this regard, Vygotsky (1978:90) is of the opinion that when learning takes place, a number of internal processes are initiated that can only operate when students are interacting with peers in their environment or through cooperation with their peers. The literature as well as the experience in the SASL class once again prompts the creation of learning communities for the acquisition of academic discourses. Consequently, the value of pair work, group work (Holmes et al. 2001:2-3) and online collaboration (MacDonald 2008:161-162, 164, Nel 2005:20, 35) in the teaching of academic discourses should not be underestimated.

\section{Code: Giving tools to learn}

Lecturers should not only focus on learning outcomes in isolation, but should also bear in mind the means or skills needed to reach the outcomes.

2.31: Many students spontaneously started taking notes as new signs were introduced to us. Here I felt that it is quite difficult to represent an actual sign language 'word' or 'phrase' as a description on paper. Only after we did a couple of words, did the interpreter/co-lecturer briefly explain how to record these signs.

2.46: I also wished the lecturer could help with ways in which to remember signs.

Participants attending the SASL course were confronted with a number of signs that had to be acquired and, apart from recording signs (which not all of the participants could do), notes had to be made. Reducing sign language signs to descriptions and drawings during class demonstrations proved to be very difficult as we did not have any prior knowledge on how to codify signs. The description on how to transcribe signs, provided by the interpreter and colecturer, demonstrated how complex it is to adequately describe signs. This includes, amongst other things, facial expressions, what is done with the hands and where in relation to the body this is done. Due to time constraints, most participants opted for their own methods of documenting signs on paper. Similarly, it is important to provide students with tools to acquire the necessary skills via courses in which academic discourses are taught. Sometimes 
these tools act to bridge the gaps between what is expected at school against what is expected at university level. Another issue that stood out from the classes was acquired skills being measureable.

\section{Code: Measureable skills}

Although not everything done in classes at university level is measureable at once, this measurability is valuable.

2.18: You can easily determine whether or not you have acquired the finger spelling alphabet.

We appreciated the fact that our progress in acquiring finger spelling skills and basic signs was visible or measureable. You could either do (or remember) it or not, and this served as motivation to work harder at issues such as grammar or practising signs that were not that obvious. This experience prompts the question as to whether the outcomes set in courses dealing with academic discourses also involve aspects that students can measure throughout the duration of a course. Hence, clear instructions and assessment criteria should be provided for all tasks and assessment opportunities. Repetition of acquired skills also seemed to be a prominent aspect drawn from the data, as will be explained in the following subsection.

\section{Code: Repetition}

Quite some time in the SASL course was spent revising or repeating learnt signs.

1.07: Practising the alphabet over and over made me feel confident.

2.13: At the start I struggled to remember all the letters of the finger spelling alphabet. I had to interrupt the lecturer after the first ten letters so that he could repeat them to the class. In the end the repetition helped a lot.

2.67: Difficult signs combined with not practising makes classes challenging. I do feel I could have done more, but I did not have the time!

Despite some confidence gained from practising certain sign language skills, repetition did not ensure acquisition of sign language. This ties in with the literature, where the use of repetition in language acquisition is seen to be suspect. As such, Van Patten and Benati (2010:141) are of the opinion that "repetition may aid the development of explicit knowledge in the short run, and explicit knowledge exists as a separate system from the implicit knowledge that forms competence". It is therefore important that when academic discourses are taught, students should be engaged in using these discourses in appropriate, significant and communicative contexts.

\subsection{Further reflection}

About nine months after completing the SASL course, we have totally different competencies regarding SASL. We both used to have contact with the Deaf colleague and therefore could use the skills we acquired quite often. Since the completion of the course, one of us has moved to another office in a different building and now has little contact with the Deaf colleague and has forgotten most of the finger spelling and signs. On the other hand, the other 
author still has regular contact with the colleague and, despite having forgotten some of the signs, this person can maintain discussions with the Deaf colleague and has even learnt some new words and phrases. Interestingly, the other colleagues that attended the course used to use sign language with each other when meeting up in corridors, but this only lasted while the course was going on. It is clear that they no longer have any purpose in practising signs with each other.

In terms of the teaching of academic discourses, the aforementioned reflection also relates to transfer of skills learnt in the first-year Afrikaans and Dutch and compulsory academic literacy modules. A once-off introduction of skills to be used for undergraduate essays, minidissertations or maybe even only at postgraduate level, is not sufficient. Reinforcement and revision of academic discourse skills is required throughout students' academic careers. Even continued cross-disciplinary team-teaching (Kutz 1986:389) could be beneficial in this regard. Lecturers should create academic communities in which academic discourses are taught that are relevant and that can be transferred throughout students' time in academia.

\section{Findings}

Only through reflection can we learn what we already know and begin to understand what we need to learn next (Yancey 1998:143). We have found that through reflection we not only learn how and what to learn, but also how to improve our teaching. In this regard, Jay (2003:1) notes that "[f]or many accomplished teachers acclaimed for the quality of their practice, to do so involves on-going reflection". We can add that placing oneself in the same context as one's students is also important for a richer reflection process.

From the data analysis of our reflections in a second language class, a number of conclusions can be drawn regarding the improvement of the instruction of academic discourses. The first set of codes related to the appropriateness of the learning context. The pace maintained in class and the way in which lessons are structured must be adapted so that they meet students' needs and ideally be customised towards each class and maybe even individual student needs. In addition, students should be aware of long-term goals as well as short-term lesson outcomes. This setting of outcomes implies not only knowing the rationale of a course, but also having structure to the learning experience.

Motivation is a key requirement for successful acquisition of any language and, by implication, discourses. In this study, becoming part of or just accessing the Deaf community was an important motivational factor. The challenge is to replicate that circumstance in classes focusing on academic discourses. A further issue is accommodating different learning styles and needs in classes. A solution to accommodating different learning styles is by working towards differentiation in class. What may be useful here is the use of non-academic discourses as well as establishing continued dialogue between lecturers and students regarding pedagogical practices and the rationale behind certain choices. Furthermore, a balance should be established between the introduction of new content and some practice or revision of already-taught content.

Specific issues were also identified in terms of the improvement of teaching and learning practices. The use of a safe learning environment is evident. Specifically, the maintenance of learning communities can aid in this regard. Not only was the introduction to the Deaf 
community achieved, albeit only through contact with the Deaf lecturer, benefits were also clear from the creation of a learning community that contributed to learning. Using technology to support learning is useful, especially when recordings can be shared online after class. These issues prompt the question as to how lesson capturing could be used effectively in teaching academic discourses. It is important that a balance of content be maintained between lessons and even during lesson phases. The amount of content and the duration of a course should also be borne in mind. An academic semester or a year for the introduction of academic discourses is questioned.

In terms of other pedagogical issues, the use of examples and learning tools, focusing on measureable skills and repetition, were also identified. Apart from individual practice, the learning community allowed copying signs. In this respect, collaboration in pairs or in groups is essential. Lecturers should ensure that students not only know which outcomes they have to achieve, but also have the tools in order to achieve these outcomes. The simple problem of transcribing SASL signs proved to be a major barrier. In terms of academic discourses, unexpected or even seemingly simple challenges such as spelling, grammar, text structuring, cohesion, coherence, referencing, plagiarism or even computer literacy should thus not be ignored. The outcomes set as well as the knowledge and skills they entail, should be measureable so that students can be aware of their progress (or limitations) throughout the learning process. The benefits of repetition should be acknowledged but, without any engagement in communicative contexts, repetition might not yield adequate results. Kutz (1986:388) also emphasises communicative need and real contexts as requirements for language acquisition. Finally, continued use and enforcement of academic discourse skills, apart from literacy and language courses, are important in order to ensure acquisition and transferability of skills to later stages of a student's academic life.

The aforementioned findings support the notion that not only the process of second language acquisition relates to the acquisition of academic discourses, but also that exposure to a second language acquisition context (and reflection thereof) can contribute to better pedagogical practice.

\section{Conclusion}

Through reflection, parallels were apparent between the acquisition of academic discourses and the acquisition of second languages. With regard to the teaching of academic discourses, the need for exposure to second language acquisition and at least relevant theories is clear. Concerning the learning context, student needs in terms of pace, lesson structure and motivation should be taken into account. The creation of learning communities within safe learning environments, supported by effective use of technology, seems to be an integral ingredient for the teaching of academic discourses. Finally, adequate balance in terms of content, the creation of opportunities for learning by example, having sufficient tools to reach measureable outcomes as well as creating opportunities for reinforcement of skills could benefit the teaching of academic discourses.

The value of reflection should also be emphasised as it has proved to be a valuable tool for improving pedagogical practice. It is important, as it was for Atticus Finch in To Kill a Mockingbird (Lee 1960:35), that "[y]ou never really understand a person until you consider things from his point of view, [...] until you climb into his skin and walk around in it". 


\section{References}

Aarons, D. and P. Akach. 2002. South African Sign Language: One language or many? In R. Mesthrie (ed.) Language in South Africa. Cambridge: Cambridge University Press. pp. 127147.

Akach, P. and J.A. Naudé. 2008. Empowering marginalised culture: The institution of South African Sign Language. Journal for New Generation Sciences 6(3): 3-21.

Andrusyszyn, M. and L. Davie. 1997. Facilitating reflection through interactive journal writing in an online graduate course: A qualitative study. Journal of Distance Education 12(1/2): 103-126.

Atlas.ti. 2014. Atlas.ti qualitative data analysis software. Version 7.1.7. Available online: http://www.atlasti.com/ (Accessed 17 March 2014).

Badger, R. and G. White. 2000. A process genre approach to teaching writing. ELT Journal 54(2): 153-160.

Boud, D., R. Keogh and D. Walker. 1985. What is reflection in learning? In D. Boud, R. Keogh and D. Walker (eds.) Reflection: Turning experience into learning. London: Kogan Page. pp. 7-17.

Boughey, C. 2000. Multiple metaphors in an understanding of academic literacy. Teachers and Teaching: Theory and Practice 6(3): 279-290.

Brown, A.V. 2009. Students' and teachers' perceptions of effective foreign language teaching: A comparison of ideals. The Modern Language Journal 93(1): 46-60.

Druchen, B. 2007. Memorandum towards recognition of South African Sign Language as the 12th official language. Available online: http://www.pmg.org.za/docs/2007/070216memorandum.htm (Accessed 8 May 2013).

Elbow, P. 1991. Reflections on academic discourse: How it relates to freshmen and colleagues. College English 53(2): 135-155.

Ellis, R. 1985. Understanding second language acquisition. Oxford: Oxford University Press.

Fraser, W.J. and R. Killen. 2003. Factors influencing academic success or failure of first-year and senior university students: Do education students and lecturers perceive things differently? South African Journal of Education 23(4): 254-260.

Gass, S.M. and L. Selinker. 2008. Second language acquisition: An introductory course. New York: Routledge.

Gee, J.P. 1989. Literacy, discourse, and linguistics: An introduction. Journal of Education 171(1): 5-17. 
Guilloteaux, M.J. and Z. Dörnyei. 2008. Motivating language learners: A classroom-oriented investigation of the effects of motivational strategies on student motivation. TESOL Quarterly 42(1): 55-77.

Henderson, R. and E. Hirst. 2006. How sufficient is academic literacy? Re-examining a shortcourse for 'disadvantaged' tertiary students. Paper presented at the Australian Association for Research in Education Annual Conference 2006: Engaging Pedagogies, 27-30 November 2006, Adelaide, South Australia. Available online: https://eprints.usq.edu.au/1598/2/Henderson_Hirst_AARE 2006_PV.pdf (Accessed 15 March 2014).

Holmes, B., B. Tangney, A. Fitzgibbon, T. Savage and S. Mehan. 2001. Communal Constructivism: Students constructing learning for as well as with others. Proceedings of the 12th International Conference of the Society for Information Technology and Teacher Education (SITE 2001), Charlottesville, VA, USA. Available online: http://www.scss.tcd.ie/publications/tech-reports/reports.01/TCD-CS-2001-04.pdf (Accessed 17 March 2014).

Hyland, K. 2009. Academic discourse: English in a global context. London: Continuum.

Jackson, L., W. Meyer and J. Parkinson. 2006. A study of the writing tasks and reading assigned to undergraduate science students at a South African university. English for Specific Purposes 25(3): 260-281.

Jay, J.K. 2003. Quality teaching: Reflection as the heart of practice. Oxford: The Scarecrow Press.

Jordan, R.R. 1997. English for academic purposes: A guide and resource book for teachers. Cambridge: Cambridge University Press.

Krashen, S. 1981. Second language acquisition and second language learning. London: Pergamon.

Kreber, C. 2002. Teaching excellence, teaching expertise, and the scholarship of teaching. Innovative Higher Education 27(1): 5-23.

Kutz, E. 1986. Between students' language and academic discourse: Interlanguage as middle ground. College English 48(4): 385-396.

Larrivee, B. and J.M. Cooper. 2006. An educator's guide to teacher reflection. Boston: Houghton Mifflin.

Lee, H. 1960. To kill a mockingbird. Oxford: Heinemann.

Lillis, T. and J. Turner 2001. Student writing in higher education: Contemporary confusion, traditional concerns. Teaching in Higher Education 6(1): 57-68. 
Littlewood, W. 2004. Second language learning. In A. Davies and C. Elder (eds.) The handbook of applied linguistics. Malden, MA: Blackwell. pp. 501-524.

MacDonald, J. 2008. Blended learning and online tutoring: A good practice guide. Hampshire: Gower.

Nel, E. 2005. Creating Meaningful Blended Learning Experiences in a South African Higher Education Classroom: An Action Inquiry. Unpublished $\mathrm{PhD}$ thesis, University of the Free State.

O'Brien, T. and D. Guiney. 2001. Differentiation in teaching and learning: Principles and practice. London: Continuum.

Olivier, L. and J. Olivier. 2013. The influence of affective variables on the acquisition of academic literacy. Per Linguam 29(2): 56-71.

Peirce, B.N. 1995. Social identity, investment, and language learning. TESOL Quarterly 29(1): 9-31.

Saldaña, J. 2009. The coding manual for qualitative researchers. Los Angeles: Sage.

South Africa. 1996. Constitution of the Republic of South Africa as adopted by the Constitutional Assembly on 8 May 1996 and as amended on 11 October 1996 (B34B-96).

Street, B. 2004. Academic literacies and the 'new orders': Implications for research and practice in student writing in higher education. Learning and Teaching in the Social Sciences 1(1): 9-20.

Swales, J.M. 1990. Genre analysis: English in academic and research settings. Cambridge: Cambridge University Press.

Trigwell, K. and S. Shale. 2004. Student learning and the scholarship of university teaching. Studies in Higher Education 29(4): 523-536.

Van Patten, B. and A.G. Benati. 2010. Key terms in second language acquisition. London: Continuum.

Vygotsky, L.S. 1978. Mind in society: The development of higher psychological processes. Cambridge, MA: Harvard University Press.

Yancey, K.B. 1998. Reflection in the writing classroom. Logan, UT: Utah State University Press. 